\title{
ANALISIS TERJEMAHAN BAHASA PERANCIS PADA NOVEL PERBURUAN KARYA PRAMOEDYA ANANTA TOER
}

\author{
Popi Miyondri \\ UniversitasPendidikan Indonesia \\ E-mail: miyondri.popi@gmail.com \\ DOI: http://dx.doi.org/10.17509/bs_jpbsp.v17i1.6958
}

\begin{abstract}
Abstrak
Artikel ini mengungkapkan hasil dari analisis terjemahan ke dalam bahasa Perancis pada novel Perburuan karya Pramodya Ananta Toer. Novel ini diambil sebagai sumber penelitian dikarenakan novel ini telah memenangkan penghargaan Balai Pustaka pada tahun 1949 di Jakarta dan menggambarkan ideologi orang Indonesia dan penjajah Jepang pada masa kolonialisasi Jepang. Studi ini dilaksanakan untuk menjawab dua pertanyaan yang diajukan diantaranya bagaimana penerjemah menerjemahkan novel Perburuan tersebut?, dan apakah penerjemah merupakan penerjemah setia atau penerjemah tidak setia?. Studi ini berdasarkan hasil analisis kualitatif dengan cara menganalisis hasil terjemahan dari judul, cover buku hingga kalimat - kalimat yang mengindikasikan gaya terjemahan dari penerjemah Perancis. Peneliti menganalisis hasil data tersebut dengan menggunakan teori - teori terjemahan seperti teori terjemahan post - kolonial dan teori terjemahan budaya untuk negara dunia ketiga sebagai acuan untuk menganalisis novel terjemahan yang berjudul Le Fugitif oleh François-René Daillie. Hasil dari analisis ini mengungkapkan bahwa penerjemah merupakan penerjemah yang setia berdasarkan konteks atau isi dari novel Perburuan, sehingga gaya penerjemahannya mendekati dengan versi asli walaupun ada unsur-unsur yang disesuaikan dengan pembaca yang berbahasa Perancis.
\end{abstract}

Kata kunci: terjemahan, bahasa, novel, teori terjemahan post-kolonial

\section{ANALYSIS THE TRANSLATION INTO FRENCH LANGUAGE OF NOVEL PERBURUAN BY PRAMOEDYA ANANTA TOER}

\begin{abstract}
This article reveals the results of this analyze the translation into French language of novel Perburuan by Pramoedya Ananta Toer. This novel has chosen as our resource of this research because this novel has won the Balai Pustaka award in 1949 in Jakarta and this novel describes the ideology of the people in Indonesia and Japanese colonizer in Japanese colonization period. This study was conducted to answer our two questions, such as how translator translates the novelPerburuan and is the translator is a faithful translator or unfaithful translator?. This study is based on qualitative research by analyzing the translation of title, book cover and also the phrases translated which has indicated a translation style of French translator.we analyze this data by using the theories of translation such as postcolonial translation theory and cultural translation theory for third word countries as our references to analyze the novel translated intitledLe Fugitif by François-René Daillie. The results of this study are the translator is a faithful translator based on the contexte and content in the novel Perburuan. The style of faithful translation aims to convey the author's intention as faithfully as possible into original version to the French readers.
\end{abstract}

Keywords: translation, language, novel, post-colonial translation theory 


\section{PENDAHULUAN}

Terjemahan adalah tindakan transmisi teks dalam satu bahasa (bahasa sumber) ke bahasa lain (bahasa target). Menghubungkan dua budaya, dua bahasa dan kadang-kadang dua periode. Seperti menurut Catford (1965, p. 20) terjemahan dapat diartikan sebagai berikut: penggantian materi tekstual dalam satu bahasa dengan bahan teks yang setara dalam bahasa lain.

Terjemahan yang berfokus kepada novel, puisi dan lain-lain disebut terjemahan sastra. Untuk menerjemahkan karya sastra dibutuhkan keterampilan gaya, pengetahuan budaya dan kemampuan imajinatif. Oleh karena itu, terjemahan sastra adalah tindakan manipulasi. Andre Lefevere memperkenalkan konsep manipulasi terhadap terjemahan, karena konsep ini membantu untuk menghapuskan batas-batas yang ada dan dengan demikian, memanipulasi bisa digunakan dalam penerjemahan (1992, p. 51). Dalam sebuah teks post-kolonial, gaya penerjemahan pun harus diperhatikan agar pesan dan kejadian yang ada dapat tersampaikan. Maria Tymoczko dalam Basnett dan Trivedi (2002, p. 19) mengatakan bahwa terjemahan merupakan sebuah metafor atau kiasan untuk karya post-kolonial seperti contoh terjemahan berhubungan dengan makna etomologi suatu kata dan terjemahan merupakan suatu aktivitas untuk melintasi baik itu waktu dan tempat.

Untuk itu, peneliti menganalisis sebuah terjemahan perancis dari novel indonesia, Perburuan. Pada artikel ini, penulis menganalisis novel Perburuan karya Pramoedya Ananta Toer, yang dalam versi bahasa Prancis berjudul Le Fugitif. Peneliti tertarik pada buku ini karena buku ini memenangkan penghargaan bergengsi Balai Pustaka pada tahun 1949 di Jakarta, tetapi disatu sisi buku ini juga dilarang oleh pemerintah karena dianggap mengandung unsur komunisme. Novel ini menggambarkan bagaimana sejarah kita pada saat masa penjajahan Jepang. Dengan melalui terjemahan, pembaca asing dapat mengetahu bagaimana gambaran sejarah kita pada masa penjajahan jepang. Seperti yang diungkapkan oleh Delisle (2003, p. 7) bahwa sejarah dalam terjemahan merupakan sebuah perspektif seni bergambar.

Novel ini dipilih karena memiliki karakter karya sastra Indonesia selama era kemerdekaan adalah ideologi nasionalisme. Dalam Rubel dan Rosman (2003, p. 154) bahasa indonesia dari dulu merupakan bahasa yang nilaiideologinya diturunkan sebagian dari yang digambarkan oleh penuturnya ditandai sebagai bahasa kedua dan bahasa turunan. Menurut Penulis - penulis novel Indonesia pada tahun 1945 menyoroti ideologi mereka dalam tulisan mereka dan sama hal nya dengan penulis novel Perburuan. Selain itu, dalam novel perburuan menurut Kurniawan (2002, p.12) Pramoedya memberikan latar belakang sejarah Indonesia yang diwarnai feodalisme Jawa, kolonialisme Belanda, pendudukan Jepang, maupun kemerdekaan dalam karya-karyanya, Pramoedya seringkali mengkonfrontasikan prinsip kerakyatan dan kemanusiaannya dengan sikap kesewenangwenangan dan penindasan. Jadi untuk mengetahui gaya terjemahan novel ini, kita menggunakan teori terjemahan. Teori postkolonial dan teori terjemahan budaya dunia ketiga untuk menemukan jawaban atas masalah kita pada dua pertanyaan: bagaimana penerjemah perancis menerjemahkan novel ini? Apakah dia seorang penerjemah setia atau tidak setia?.

Dengan menjawab pertanyaan tersebut, memiliki hipotesis bahwa meskipun penerjemah adalah seorang penerjemah setia, ia mencoba untuk menerjemahkan novel dengan melakukan penyesuaian dengan pembaca asing yang berbahasa Perancis, agar mereka dapat mengerti isi dari novel Indonesia.

Untuk menjelaskan secara rinci hipotesis penelitian ini, peneliti menggunakan dua teori yang terkait dengan penelitian, yaitu teori terjemahan post-kolonial dan teori 
terjemahan budaya untuk negara-negara dunia ketiga.

Dalam semantik, istilah post-kolonial istilah mungkin hanya berfokus pada budaya nasional setelah runtuhnya rezim penjajahan. Selain itu, istilah ini dapat dipahami dalam beberapa konteks sebagai periode setelah akhir penjajahan. Memang, ada teori yang telah menyebabkan studi untuk memeriksa apa yang terjadi pada periode pascakolonial. Hal ini disebut teori postkolonial. Banyak peneliti fokus pada negara-negara dijajah oleh Eropa. Mereka juga mempelajari neokolonialisme yang merupakan pengaruh kolonial dalam kaitannya dengan kesadaran untuk berpikir, berbicara dan bertindak kegiatan budaya dalam masyarakat. Karena neokolonialisme jangka, itu muncul di bawah negara-negara dunia pertama, dunia kedua dan dunia ketiga.

Ekspresi ini membantu kelompok di dunia dengan tiga kategori utama. Negaranegara dunia pertama adalah negara-negara demokratis yang warganya standar hidup yang tinggi dan maju di bidang teknologi. Negara-negara dunia kedua diindikasikan untuk negara-negara dengan ekonomi sosialis di bawah pengaruh Uni Soviet. Dan istilahi untuk negara-negara berkembang disebut negara-negara dunia ketiga.

Teori post-kolonial di Indonesia memiliki tiga makna. Pertama, akhir penjajahan di dunia. Kedua, semua catatan yang berhubungan dengan pengalaman kolonial dari abad ketujuh belas hingga saat ini. Ketiga, semua karya atau buku atau artikel yang terkait dengan paradigma superioritas Barat untuk inferioritas Timur, baik sebagai orientalisme, imperialisme dan kolonialisme (Fazil, 2016).

Yang pertama berarti memahami periode pasca-kolonial di Indonesia yang dimulai pada abad pertengahan, ke-20 setelah deklarasi kemerdekaan pada tahun 1945 hingga saat ini. Kemudian pemahaman kedua mencakup semua yang ditulis sejak kedatangan penjajah Barat di Indonesia untuk pertama kalinya, dimulai dengan kedatangan penjajah Portugis dan Spanyol pada abad ke-16, diikuti oleh Belanda pada awal abad ke-17. Dan pemahaman ketiga yang paling umum, dimulai sebelum kehadiran fisik negara-negara Barat di Indonesia, negaranegara Barat telah memiliki citra tertentu dari negara-negara asia timur.

Menurut Ashcroft, Hriffiths dan Tiffin dalam bukunya The Empire Writes Back : Theory and Practice in Post-Colonial Literatures (Childs, Peter and Patrick Williams (eds). (1997, p. 3) mengatakan bahwa istilah postkolonial mencakup seluruh budaya yang dipengaruhi oleh proses penjajahan dari mulai masa penjajahan hingga saat ini. hal ini dikarenakan adanya kelanjutan dari masa penjajahan itu melalui proses sejarah tersebur.

Untuk menerjemahkan teks ke negara lain, kita harus mempertimbangkan teks apa yang kita akan menerjemahkan. Orang Barat memiliki gambaran tentang negara oriental. Jadi, di bidang penerjemahan, pembaca berharap bahwa penerjemah harus menerjemahkan konten yang sama seperti buku asli. Tapi untuk mendapatkan kesamaan, itu tidak bisa semudah yang kita bayangkan. Oleh karena itu di bidang penerjemahan, kita tahu ada yang disebut dengan terjemahan tidak setia.

Menurut kritikus, penyair, dan editor surat kabar Bhupinder Aziz Parihar, terjemahan adalah tindakan holistik yang menentang semua teori dan strategi yang diterima seperti penerjemah mengungkapkan semua visi orang lain di lingkungan lain di luar lingkungannya. Dia menambahkan bahwa terjemahan yang indah, seperti terjemahan dari Khayyam oleh Fitzgerald, berdiri di atas karya-karya seni mereka sendiri; mereka tidak harus setia dengan aslinya, namun harus menjadi seperti Fitzgerald dalam menuliskan kembali secara piawai (Kidwai, 2016). Artinya, untuk menerjemahkan pekerjaan, seseorang dapat menjadi setia dengan aslinya dalam memiliki karakteristik yang diperlukan 
seorang penerjemah yang baik. Hal ini karena ketika diterjemahkan, ada beberapa teori, strategi dan pertimbangan lainnya. Jika kita berhasil menerjemahkan dengan pertimbangan ini, ia memiliki terjemahan yang indah.

Selain itu, menurut pandangan pembaca, mereka berharap untuk mendapatkan teks terjemahan seperti teks-teks asli dan penerjemah berupaya menyampaikan konsep, struktur atau bentuk bahasa sumber ke bahasa target dan mencapai sebuah persimpangan komunikatif antara dua bahasa dan antara karya terjemahan setia dengan yang asli dan yang tidak setia. Sehingga mereka bisa paralel antara dua budaya dan dua cerita bersama-sama.

Untuk menjawab kebutuhan pembaca, penerjemah harus mencoba untuk mengirim dan menerjemahkan ke dalam bahasa lain, struktur dan sintaks dari teks asli. Dengan menerjemahkan strukturkalimatdari teks awal, penerjemah berhubungan tidak hanya dengan menerjemahkan kata demi kata namun makna sesungguhnya dan efek dari penggabungan tersebut. Dengan demikian, dari segi sintaksis, penerjemah mencoba untuk menerjemahkan teks "kalimat demi kalimat" (Basnett \& Trivedi, 2002, p. 115116).

Perbedaan yang signifikan antara sastra terjemahan dan sastra postkolonial yang jelas dan harus ditangani dari awal (Basnett \& Trivedi, 2002, p. 20-21). Perbedaan utama adalah penulis postkolonial tidak menyampaikan sebuah teks. Dia menyampaikan suatu budaya, yang dapat diartikan sebagai bahasa, sistem kognitif, literatur (yang terdiri dari sistem tekstual, gender dll), budaya material, sistem sosial dan kerangka hukum, sejarah dan lain-lain. Ini berarti bahwa penulis yang menulis karya-karya zaman penjajahan, mungkin lebih dari satu budaya atau bahasa dalam karyanya. Loomba (2005,p.19) mengatakan banyak tulisan-tulisan tentang postkolonial menekankan konsep seperti percampuran, perpecahan dan perbedaan.

Sebaliknya, para penerjemah memiliki lebih kendala. Hal ini karena penerjemah sastra disibukkan dengan perbedaan yang tidak hanya dalam bahasa tetapi dalam kisaran yang sama dari faktor budaya yang penerjemah harus sampaikan kepada penerima budaya yang berbeda. Namun, penulis postkolonial dan penerjemah memiliki tugas yang sama dimana seseorang memiliki sebuah teks, dan yang lain memiliki terjemahan dari budaya itu sendiri.

Kedua, perbedaan parameter tekanan. Seorang penerjemah dihadapkan dengan teks tetap yang mencakup unsurunsur budaya dan bahasa yang kadangkadang bisa menjadi masalah bagi pembaca. Dengan demikian, penerjemah mengalami dilema kesetiaan dengan teks asli. Ketika itu mencerminkan budaya, kadang-kadang tidak bisa setia kepada teks asli. Ini kendala dari teks dengan literalisme budaya yang sudah menjadi bagian terjemahan dalam diskusi yang berabad-abad. Namun, penulis postkolonial memilih unsur-unsur budaya untuk disampaikan kepada pembaca.

Menurut Maria Tymoczko, penulis dan penerjemah memiliki kendala yang sama untuk memutuskan atau memilih (Basnett, 2002, p. 22). Penulis tidak bisa menulis dengan bebas karena ia harus mempertimbangkan presentasi budaya sumber sejarah, ideologi, mitos, afiliasi dan patronase dalam karya sastra. Selain itu, penerjemah harus memilih elemen dari teks yang dapat melestarikan dalam terjemahan.

Saat ini, dalam dua atau tiga dekade, terjemahan telah menjadi sebuah kegiatan nyata, lebih terhormat dan produktif. Dan studi terjemahan, itu disebut studi terjemahan. Dalam konteks budaya, terjemahan memiliki peran penting untuk mengirimkan budaya lain dari berbagai negara. Ini juga merupakan sarana untuk melakukan perjalanan antar budaya. Tetapi apakah tidak ada "kekerasan" tertentu ketika penerjemah menerjemahkan buku-buku dari negara-negara dunia ketiga? 
Menurut Frantz Fanon, "berbicara suatu bahasa adalah mengambil dunia yaitu Budayanya" (1967, p.38). Dalam bukunya, ia berbicara tentang India Barat yang ingin menjadi merdeka, menggunakan alat budaya, bahasa. Dia ingin berbicara bahasa Perancis karena secara historis bahwa bahasa adalah cara untuk memecahkan masalah warga selama lima puluh tahun lebih.

Terdapat dilema dari penjajahan akulturasi Antilles negro yang ingin merdeka yang memiliki nilai-nilai dan cara ekspresi. Dilema ini juga terjadi dalam proses penerjemahan, khususnya dalam terjemahan teks-teks Antarbudaya "dunia ketiga".

Dengan menerjemahkan teks antarbudaya dari "dunia ketiga", penerjemah sengaja melakukan kekerasan sebagai rekonstruksi. Rekonstruksi ini dari teks asing sesuai dengan nilai-nilai, keyakinan dan representasi yang ada dalam bahasa target dan dikonfigurasi dalam hierarki dominasi dan keterpinggiran, dan kemudian akan menentukan produksi, peredaran dan penerimaan teks . Misalnya, Talal Asad berasumsi bahwa salah satu kebutuhan untuk mempertimbangkan antropologi sebagai disiplin holistik dalam masyarakat borjuis sebagai objek penelitian dari berbagai perusahaan non-Eropa yang telah datang di bawah dominasi ekonomi, politik dan intelektual (1975, p.103). Jadi penerapan "kekerasan" dalam terjemahan budaya nonBarat sebagai menerapkan kekuatan, yaitu kekuatan kolonial. Kekerasan ini terjadi untuk membuat pembaca mudah untuk memahami budaya lain dengan menggunakan proses naturalisasi (Dingwaney \& Maier, 1995, p.4). Menggunakan metode naturalisasi adalah untuk membuat teks diakses oleh publik.

Ada dua metode untuk menerjemahkan teks-teks antarbudaya dari "dunia ketiga", metode membudidayakan dan metode Foregnizing (Dingwaney,1995, p.7). Metode domisticating adalah nama lain dari metode naturalisasi. Metode ini membuat teks asing dapat diakses oleh pembaca asing

sehingga terjemahan tidak terasa seperti terjemahan. Namun, metode Foregnizing mengajak para pembaca untuk merasakan bahasa dan perbedaan budaya dari teks asing. Schleiemacher (Venuti, 2004, p.100) percaya bahwa metode terjemahan foreignizing dapat berguna dalam pembentukan budaya nasional, yang menempa identitas budaya asing untuk masyarakat demi mencapai otonomi politik.

Kadang-kadang "ruang" terjadi selama menerjemahkan budaya yang bertemu atau berinteraksi dengan budaya lain. Ruang ini mengacu pada transculturation (Dingwaney, 1995, p.8). Dalam transculturation, bahasa dan budaya dominan yang ditulis ulang. Ada dua pemahaman ruang ini. Pertama adalah cara untuk menerjemahkan teks untuk menjawabtujuan dari sebuah teks atau budaya yang penerjemah menerjemahkannya. Terjemahan ini mengijinkangaya hidup dan pemikiranpenerjemah dipengaruhi oleh gaya hidup dan pemikiran orang lain. Kedua, penerjemah (salah) menerjemahkan teks asing dengan sengaja mengabaikan perbedaan antara dua budaya. Walaupun telah berusaha untuk membawa kata-kata dari satu bahasa ke bahasa lain, penerjemah tidak bisa menerjemahkan ataumenemukan kata-kata yang setara. Sehingga mereka harus memahami konteks teks antarbudaya agar dapat menerjemahkannya.

\section{METODE}

Dalam mengembangkan penelitian, menggunakan metode kualitatif untuk menganalisis data dalam bentuk teks. Data dari penelitian ini adalah novel karya Pramoedya Ananta Toer, Perburuan dan versi Perancis, Le Fugitif, yang diterjemahkan oleh François-René Daillie. Dalam penelitian ini, mengembangkan teknik analisis data dalam tiga bagian:

Untuk bagian pertama, akan meneliti bentuk buku serta cover dengan mengambil kalimat-kalimat yang mengacu pada bentuk cover tersebut. Kemudian menganalisa 
terjemahannya. Kedua, menelitidari segijudul baik itu versi asli ataupun versi terjemahannya dengan dikaitkan dengan kalimat-kalimat teks yang mengacu pada judul.. Dan bagian ketiga, kita mengambil beberapa paragraf yang dirasa mencerminkan gaya terjemahan dari sang penerjemah. Dalam menganalisa terjemahan tersebut tetap mengacu pada teori terjemahan yang telah terapkan.

\section{HASIL DAN PEMBAHASAN}

Dalam penerapan teori -teori yang telah disampaikan, telah menganalisis novel Perburuan dan novel terjemahannya Le Fugitif. Peneliti membagi tiga bagian dalam bagian ini untuk mendapatkan jawaban dari dua pertanyaan untuk menguatkan hasil hipotesis.

\section{Analisis bentuk buku}

Untuk menganalisis kedua bentuk novel tersebut, peneliti sajikan hasil analisis pada buku yang diteliti berikut ini.

Tabel 1. Informasi bentuk terkait novel asli dan terjemahan

\begin{tabular}{ccc}
\hline Novel & Asli & Terjemahan \\
\hline Judul & Perburuan & Le Fugitif \\
\hline Penulis & Pramoedya Ananta Toer & Francois-René Daillie \\
\hline $\begin{array}{c}\text { Tanggal } \\
\text { penerbitan }\end{array}$ & 1950 (Première Edition) & 1990 \\
\hline Bahasa & 1994 (Quatrième Edition) & Perancis \\
\hline Penerbit & Balai Pustaka (Edisi Pertama) & Plon; 10-18 \\
\hline Format & Hasta Mitra (Edisi Ke empat) & 213 halaman $/ 20 \mathrm{~cm}$ \\
\hline
\end{tabular}

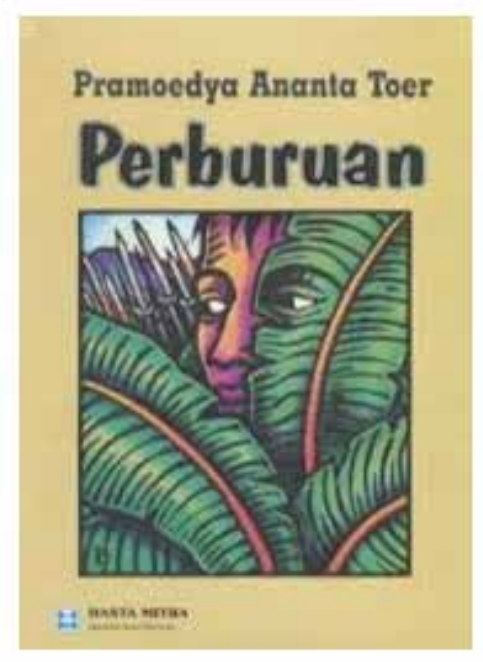

Gambar 1. Sampul buku novel Perburuan

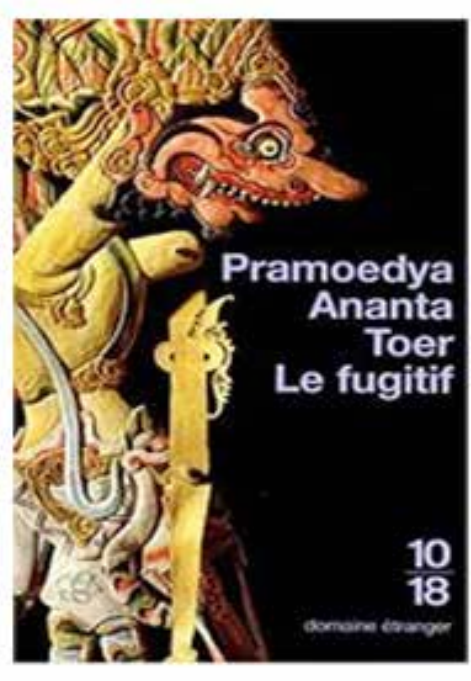

Gambar 2. Sampul buku Le Fugitif

Pertama, sampul buku asli dan menganalisis dua sampul berdasarkan buku terjemahan berbeda. Tidak ada pendapat dan informasi terkait. Sampul penjelasan mengapa sampul kedua buku novel Perburuan digambarkan oleh tersebut berbeda. Tapi mencoba untuk Bascova pada tahun 1990 dengan izin 
dari William Morrow dan Co, New York. Dalam sampul ini, ada seorang pria bersembunyi di dedaunan dan di balik itu, ada beberapa bambu tajam tongkat yang bisa berarti sebagai pagar bambu. Pria di sampul menggambarkan Hardo sebagai protagonis dalam novel ini yang bersembunyi dan lolos dari penjajah Jepang. Situasi sampul ini digambarkan setelah ia bertemu Lurah Kaliwangan, ia pergi ke tempat persembunyiannya. Kejadian ini diilustrasikan dalam paragraf berikut ini. «Pagar yang terbuat dari carang, ranting bambu yang kecil-kecil, kuning dan rapat berkilat-kilat membendalkan cahaya bulan. Di bawah pagar itu, rumput-rumput hijau tumbuh dan hidup dengan amannya. Kena sinar bulan, nampak warnanya yang hijau itu jadi tua. Pagar itu panjang meliku-liku disepanjang tepi tanggul sawah dipergunakan orang sebagai jalan. Di sebuah pagar yang terbuat dari carang tua terdapat tali bambu sebagai kunci.»

(Perburuan: p.35)

Penerjemah menerjemahkannya menjadi :

"La cloture de bambou, tressée de fines lattes serrées, avait des reflets jaunes sous la lune, dont la clarté faisait paraitre plus sombre l'herbe verte qui croissait en sureté à se base. Cette clôture suivait les contours d'un champ de riz dont la diguette servait aussi de sentier humains. Une barrière du même matériau fermait par une cordelette en fibre»

(Le Fugitif, p.49)

Peneliti meyakini bahwa terdapat juga makna yang lebih luas. Sampul ini menggambarkan tentang persembunyian. Persembunyian ini berarti bahwa orang yang bersembunyi adalah Hardo yang dikejar oleh seseorang atau banyak orang. Hal ini terbukti karena mata orang tersebut terlihat berhati-hati dan bersembunyi di dedaunan. bambu runcing melambangkan ide-ide tentang berburu dan gulat. Orang berburu Hardo karena perintah pemerintah Jepang. Di Indonesia, bambu runcingadalah senjata pertama diduga digunakan oleh masyarakat Indonesia sebagai sarana perlawanan terhadap penjajah Belanda. Pada saat itu, bambu runcing yang digunakan oleh berbagai daerah di Indonesia untuk melambangkan keberanian dan pengorbanan dalam mencapai kemerdekaan. Isu-isu ini dikembangkan selama pendudukan Jepang, yang dikenal sebagai takeyari. Senjata ini digunakan untuk memblokir pasukan udara musuh yang diterjunkan dari udara (Isnaeni, 2014).

Alat yang digunakansaatpertempuran seperti bambu runcing digunakan oleh para tentara Keibodan (tentara jepang) untuk mengejar Hardo. Seperti yang terangkum dalam paragraf pada teks Perburuan :

... Nampak olehnya di depan orang keibodan bersenjata bambu runcing berlari-larian masuk ke ladangnya dan menuju gubuk.

(Perburuan, p.74)

Ujung-ujung bambu runcing diminyaki dengan minyak jarak dan dibakar hitam sedikit dan mengkilatkilat kena cahaya api.

(Perburuan, p.75)

Dalambahasa Perancis diterjemahkan menjadi :

Il vit huit hommes de la keibodan armés de lances de bambou entrer en courant dans son champ et se diriger vers la cabane

(Le Fugitif, p.98)

La pointe de leur lance de bambou, enduite buile de ricin et légèrement brunie au feu, brillait à la lueur des flammes qui accusait nettement leurs traits cruels.

(Le Fugitif, p.98)

Dalam terjemahan pertama, penerjemah menunjukkan ada 8 orang. Namun dalam novel Perburuan, Pramoedya tidak meunjukkan berapa jumlah Keibodan yang mengejar Hardo. Dalam sampul novel 
terjemahan, sampulnya menggambarkan boneka Indonesia yang disebut Wayang. Wayang merupakan salah satu pertunjukan di Indonesia yang dihidupkan oleh para pribumi yang berada di Jawa dan Bali. Pertunjukkan ini memang sangat terkenal di beberapa daerah seperti Sumatra dan semenanjung melayu yang juga mempunyai budaya wayang yang disebarkan oleh budaya jawa dan hindu. Pada tanggal 7 November 2003, Wayang ditetapakan sebagai pertunjukan boneka yang terkenal di Indonesia oleh UNESCO yang merupakan organisasi di bawah naungan PBB yang menangani masalah pendidikan, ilmu pengetahuan dan kebudayaan. Selain itu, wayang juga dianggap sebagai mahakarya warisan manusia.

Dalam Rumambi (2011) Para pemeran wayang mewakili karakter-karakter yang kompleks. Tema dalam cerita wayang adalah pertempuran. Pertempuran ini tidak hanya sekedar tentang kebaikan atau keburukan melainkan nafsu manusia. Diantaranya ada rasa benci, percintaan, pengorbanan, penghianatan dan keramahan. Sehingga karekter yang baik merupakan karakter yang dapat mengontrol emosi dan nafsu. Selain itu, dalam novel ini, penulis menunjukkan filosofi dari wayang di antaranya:

Gung dan Gendang yang berirama itu mengiringi mainan wayang yang sampai pada babak perang kembar, peperangan antara gergasi dengan kesatria, antara kebinatangan dan budi kemanusiaan.

(Perburuan, p.69)

Ils accompagnaient de leur battement rythmé le spectacle du théâtre d'ombres, qui en arrivait à l'épisode où la guerre bat son plein - la bataille entre Orges et Héros, entre sauvagerie animale et raison humaine.

(Le Fugitif, p.91)

Filosofi wayang yang diilustrasikan oleh para pemain dalam novel ini sehingga ilustrator dari sampul novel terjemahan menggunakan karakter wayang sebagai simbol pemain dalam novel indonesia.

\section{Analisis judul buku}

Penulis mempresentasikan judul dari karyanya untuk menggambarkan karyanya. Ini merupakan salah satu bentuk metadata yang berarti sebuah data yang digunakan untuk mendefinisikan atau menggambarkan data yang lain sebagai pendukung (baik secara cetak ataupun elektronik). Metadata merupakan: (1) informasi yang menggambarkan isi berupa objek nyata atau abstrak, dan (2) label yang menunjukkan data. Judul merupakan salah satu bentuk metadata. Judul pada teks tersebut berfungsi untuk memberikan sebuah kutipan atau sebuah nama di dalam karya tersebut. Judul tersebut sesuai dengan aturan yang ada.

Dalam novel asli, Perburuan merupakan suatu kata benda. Berdasarkan Kamus Besar Bahasa Indonesia (KBBI), Perburuan berarti :

Perburuan / per-bu-ru-an/: (a) Binatang yang diburu; buruan; (b) Alat perlengkapan dan sebagainya untuk berburu; (c) Tempat untuk berburu; (d) Yang berkaitan dengan kegiatan berburu dan pengurusannya.

Dalam bahasa Perancis, kata Perburuan diartikan sebagai La chasse [n.f] yang dalam kamus bahasa Perancis diartikan:

(a) action de chasser, de poursuivre pour capturer on tuer à des fins utilitaires on par goût sportif (tindakan memburu, mengejar untuk menangkap, atau membunuh demi tujuan utiliter); (b) Chasse aux animaux de haute taille (pengejaran binatang besar); (c) Chasse au cours de laquelle on imite les cris des animaux pour les attirer (Berburu sambil meniru teriakan binatang untuk menarik perhatian binatang tersebut); (d) Détermination par le lieu où se déroule la chasse (Penentuan tempat dimana perburuan itu dilakukan).

Namun sangat disayangkan, peneliti tidak menemukan alasan mengapa penulis, memberikan judul Perburuan, mengapa dia tidak memilih judul Pemburuan?. Hal ini 
dikarenakan, pemburuan berdasarkan kamus besar bahasa indonesia, kata tersebut lebih cocok karena mengandung makna proses, cara, tindakan berburu; pengejaran. Sehingga peneliti menyimpulkan bahwa Pramoedya Ananta Toer memberikan judul Perburuan pada novelnya untuk menekankan bagaimana pemburuan terhadap Hardo oleh penjajah Jepang dan bagaimana Hardo dikejar oleh penjajah Jepang. Berdasarkan isi dan judul buku tersebut, penulis menceritakan bagaimana pengejaran tersebut. Seperti dalam bukunya :

Kalimat di bawah ini menunjukkan situasi ketika Hardo bertemu Ayahnya. Namun ayahnya tidak mengenalnya dikarenakan Hardo terlihat seperti seorang pengemis dan dia tidak bisa melihat Hardo secara jelas dikarenakan umurnya yang sudah tua. Lalu ayahnya menceritakan bagaimana pengejaran terhadap Hardo oleh Penjajah Jepang.

1. “... mungkin anakku sudah mati. Nippon tak mau kenal ampun pada musuhnya"

2. "... anakku berontak melawan bala tentara Dai Nippon. Tiga shondaco yang berontak. Dan mereka itu berontak pada shodannya..." kata ayah Hardo. Dan Hardo menjawab "Dan kalau aku tak salah dengar pmberontakan itu gagal". Ayah Hardo menjawab " ya, gagal... dan kabar mengatakan seorang diantara ketiga shobanco itu ada yang berkhianat...”

3. “ Apalagi kalau pemerintah itu pemerintah militer sebagai Nippon yang gampang sekali memotong orang 4. " kemudian aku mendapat telegram dari pemerintah. ... aku diperintahkan untuk mengerahkan rakyat mengepung anakku sendiri."

" telegram datang lagi, anakku tampak di pegunungan cadas Platungan dan aku mendapat perintah mengepung lagi"

(Perburuan, p.46-47)
Terjemahan dalam bahasa Perancis :

1. “... peut-être qu'il est mort. Les Japonais ne passent pas pour pardonner à leur ennemis"

2. "... c'était celle de la rébellion de mon fils contre les forces armées japonaises avec deux autres shondancho et leurs hommes, qu'ils avaient entrainés avec eux." Dit- le père de Hardo. Hardo a répondu "la rébellion en question a échoué". Et cette phrase a été justifié par son père "Oui, échoué ... et la nouvelle disait aussi que c'était l'un des trois shodancho qui avait trabi"

3. "A plus forte raison s'il s'agit d'un gouvernement militaire comme celui $d u$ Japon, qui n'bésiterait pas un instant à vous faire couper le cou!"

4. Lorsque le gouvernement japonais chasse son fugitif, le gowvernement passerait les messages à travers plusieurs fois par télégramme à toute la communauté. Comme dans la phrase racontée par le père de Hardo: “... Ensuite, j'ai reçu du gouvernement un télégramme, ordre donne à moi, son père, de rassembler tous les gens du pays pour encercler mon propre fils"

"... Un autre télégramme est arrivé: on avait vu mon fils dans les montagnes rocheuses de Platungan. Et avec ça, ordre à nouveau de l'encercler'.

$$
\text { (Le Fugitif, p.62-63) }
$$

Selain itu, dalam buku Perburuan, penulis menunjukkan secara gamblang dalam kalimat yang Dipo katakan kepada Hardo untuk menggambarkan bahwa mereka adalah buronan.

Sayang, keluh Dipo, kita kenal Karmin sesudah dia berkhianat, sesudah kita jadi binatang perburuan.

(Perburuan, p.96)

Dommage, soupira Dipo, que nous n'ayons vraiment appris à connaitre Karmin qu'après sa trabison - après être devenus gibier!

(Le Fugitif, p.124) 
Terjemahan dari judul Perburuan ke dalam bahasa Perancis Le Fugitif berdasarkan kamus bahasa Perancis adalah : (a) (Celui, Celle) qui s'échappe ou qui est en fuite (Orang yang melarikan diri atau orang jalanan); (b) (Celui, Celle) qui est banni ou qui fuit son pays (orang yang dilarang atau melarikan diri dari negaranya); (c) Qui passe, qui apparaît très brièvement (orang lewat atau yang muncul sebentar saja)

Berdasarkan pengertian tersebut, dapat peneliti simpulkan mengapa judul pada buku terjemahan berbeda dengan judul aslinya. Penerjemah memilih judul tersebut untuk menekankan pada karakter pemain dalam buku Perburuan seperti Hardo dan Dipo yang dikejar oleh penjajah Jepang.

\section{Analisis gaya terjemahan novel Perburuan}

Pada bagian ini, mengungkap analisa pada gaya terjemahan penerjemah dalam novel terjemahannya LeFugitif. menampilkan beberapa terjemahan penting agar kita dapat mengetahui bagaimana penerjemah menerjemahkan novel Perburuan.

a. Lebih baik jangan. Menahan pèrempuan bukan satria. Dan sidokan goblok itu memuji perkataan Karmin yang kosong itu.

(Perburuan, p.96)

- Il a dit, comme ca: «vaux mieux pas arreter la jeune fermme, ce serait contraire à l'esprit chevaleresque.» Tu parles d'un bla-bla! Et cet imbécile de sidokan qui se repandait en lonanges sur lui à ce propos!

$$
\text { (Le Fugitif, p.125) }
$$

Dalam terjemahan tersebut, penerjemah menyampaikan ide pada kaliamat tersebut namun ada perubahan struktur kalimat. Pada versi terjemahan, penerjemah tidak menerjemahkan kalimat “...dan sidokan goblok itu memuji perkataan Karmin yang kosong itu" yang jika diterjemahkan ke dalam bahasa Perancis menjadi "... et le stupide sidokan a loué des mots vides de Karmin”. b. ... Buatan jepang beginilah jadinya sekarang. Mereka membangun penghormat pada diri sendiri sambil menunjukkan kebiadaban musuhnya. Tapi Nippon dengan tiada disadarinya membuat kuburnya sendiri. Dikiranya orang Indonesia tak ada merasa sesuatu keburukan dan kehinaan pada badannya. Hmm, akhinya indonesia sadar juga akan keganasan gurunya.

(Perburuan, p.57)

Penerjemah menerjemahkan obrolan ayah Hardo menjadi:

"C'est la faute des Japonais si les choses en sont venues là. Ils exaltent le sens de l'honneur chez, leurs semblables tout en traitant leurs ennemis comme des sauvages. Mais sans s'en rendre compte, ils sont en train de creuser leur propre tombe. Ils croient que les Indonésiens ne voient pas en eux la moindre bassesse. Eh bien, si les Indonésiens sont pleinement conscients de la cruauté de leurs maîtres d'ecole!»

(Le Fugitif, p.76) Penerjemahan di atas masih setia dengan novel asli di sebagian besar teks.

c. Diam! Bentak jepang itu mengulangi. Indonesia tidak boleh bicara-bicara kalau tidak ditanyai. Indonesia harus diam saja, ya!? Sekarang suaranya jadi cepat dan patah-patah. Kalau Ondonesia ada di depan Nippon, ya? Nippon, ya? Tidak boleh bicarabicara mendongeng-dongeng. Itu nona mesti tahu. Matanya melotot, Indonesia tidak bagus. Indonesia mesti belajar diam dan tutup mulut, ya mengerti?

(Perburuan, p.149)

- Silence! burla de nouveau le Japonais, Indonésiens pouvoir rien dire si pas interrogés. Rien dire. Indonésien seulement se taire, c'est tout. 
Son débit se fit plus rapide et haché.

- Quand vous Indonésiens être devant Japonais ... Japonais, comprenez, hein?... pas raconter bistoires à lui. Vous, mademoiselle, devez savoir, lui dit-il en roulant de gros yeux. Indonésiens pas bons. Indonésiens devoir apprendre se taire, fermer la gueule, bein? Comprendrez, mademoiselle? Comprendrez?

Penerjemah menerjemahkan sama dengan novel tersebut walaupun ada beberapa kata atau kalimat tambahan agar dapat diadaptasi oleh bahasa target, bahasa perancis.

d. ... tidak tuan, katanya membela kebenarannya. Betul tidak! Katanya gugup dan tangannya terangkat sedikit. Aku bersumpah, tuan. Betul... Raden Hardo tadi malam ada di Kaliwangan. Dan dia menyamar sebagai pengemis. Aku sendiri melihat dia. Aku sendiri melihat dengan mataku sendiri. Dan kira-kira sepèrempat jam aku bercakap-cakap dengannya. Barangkali lebih dari sepèrempat jam. Mungkin setengah jam.

(Perburuan, p.114)

Terjemahan bahasa Perancisnya menjadi :

- Non, non, bonorable sidokan, dit-il, pris de panique, les mains levées, ce n'est pas une erreur, je peux vous le jurer! Hardo se trowver bel et à bien à Kaliwangan hier soir. Et il était déguisé en mendiant. Je l'ai vu, de mes yeux vu. Je l'ai vu, de mes yeux vu.J'ai discuté avec lui pendant près d'un quart d'heure. Peut-être même plus que ca, une demi-heure.

(Le Fugitif, p.146)

Dalam terjemahan ini, penerjemah memberikan ide yang sama dengan versi asli dimana Lurah melihat Hardo di Kaliwangan. Namun, dia tetap memberikan eksresi Perancis seperti versi asli. Namun, penulis tidak menggambarkan gestur akan bersumpah. Sebaliknya penerjemah seolah menggambarkan tangan terangkat seperti bersumpah. Tambahan ini memberikan kejelasan dari tindakan bersumpah. Selain itu dalam versi asli tidak ada kata panik. Namun penerjemah menggambarkan kata gugup dengan sebutan panik. Jika kita telusuri bahwa kalimat ini menggambarkan bahwa Lurah Kaliwangan sedang panik. Selain itu dia memberikan ekspresi bel et bien untuk menguatkan pernyataan Lurah Kaliwangan.

e. ... tapi kesengsaraan batin itu belum lagi sampai pada akhirnya. Telegram datang lagi ... anakku tampak di pegunungan cadas Platungan. Dan aku mendapat perintah mengepung lagi ...

(Perburuan, p.47)

- Pourtant, je n'étais pas au bout de mes pains. Un autre télégramme est arrivé : on avait vu mon fils dans les montagnes rocheuses de Platungan. Et avec ca, ordre à nouveau de l'encercler.

(Le Fugitif, p. 63)

Versi terjemahan ini menyampaikan hal yang sama, namun memiliki perubahan struktur dengan menggunakan metode domesticating.

f. ... Dulu, kawan, kala ada datang mobil ke kewedanan, alangkah senang. aku selalu gembira kalau menerima tamu-tamu tuan Nippon itu. Karena, engkau mesti tau sendiri... harapan kenaikan gaji dan pangkat! Ya, engkaumesti tahu, karena engkau bukan kere, kawan, harapan pegawai hanyalah dua : kenaikan gaji dan kenaikan pangkat.

(Perburuan, p.49)

Versi bahasa Perancis :

- Il y a eu un temps où j'aimais bien entendre les autos arriver à la sous-préfecture. J'étais toujours content de recevoir mes hôtes japonais. Pourquoi, th dois le savoir toimême :j'espérais une augmentation, ou une promotion! Oui, tu le sais surement, parce que tu n'es pas un vrai mendiant, ca, je ne le crois pas. Pour un fonctionnaire, mon ami, il n'y a pas d'autre espérance que ces 
deux-là : toucher davantage ou monter en grade! Oui bien sur, tu sais cela ...

(Le Fugitif, p. 63)

Dalam versi terjemahan ini, penerjemah menambah kalimat akhir toucher davantage ou monter en grade yang memiliki arti "kenaikan gaji dan kenaikan pangkat" yang jika diartikan une augmentation, ou une promotion, dan ini untuk menghindari kalimat yang sama dalam satu paragraf. Sebaliknya dalam versi asli, penulis menulis dua kali untuk menekankan pada kalimat "kenaikan gaji dan pangkat".

g. ... Ya, aku lihat-lihat anak sekarang seperti pendeta pertapa. Anak sekarang sudah melepaskan keduniaan seluruhnya. Hidup sebagai tualang! Ya, moga-moga berbahagialah hidup anak kelak oleh kesengsaraan dan keprihatinan ini. coba meninggalkan segala kesenangan! Sampai pun pada merokok! Sampai pada ibu dan ayahnya! Dan keluargaku tak diistimewakan lagi!...

(Perburuan, p.29)

Ucapan Lurah Kaliwangan kepada Hardo diterjemahkan menjadi :

«... Oui, tu ressembles à un ascète. Tu laissé loin derrière toi ce monde d'ici-bas. Une vie de vagabond! Puisse ta vie à venir connaitre la félicité de la souffrance et des privations. Tu te rends compte, renoncer à tous les plaisir! Jusqu'au celui de fumer! Renoncer à tes père et mère! A ma famille, que tu aimais par-dessous tout. ...»

(Le Fugitif, p.42)

Dalam terjemahan ini, penerjemah tetap setia dengan versi asli. Peneliti tertarik terhadap ekspresi "Hidup sebagai tualang". Kata "tualang" dalam bahasa indonesia memiliki dua makna, makna positif yaitu seorang petualang dan makna pejoratif yaitu gelandangan, sehingga peneliti dapat memahami bahwa makna pejoratif yang menggambarkan situasi Hardo. h. ... Engkau sekarang prajurit dan masih tetap prajurit. Engkau boleh melemparkan sumpahmu sebagai prajurit terhadap Nippon! Tetapi sumpahmu sebagai prajurit diantara kita di gua Sampur tak boleh kau abaikan. Jangan sekali-kali! Pedanglah apa yang harus kau pedang. Tembaklah apa yang harus kau tembak. Dan bila engkau sudah lepas dari kewajibanmu sebagai prajurit siapakah yang akan melarang engkau mengecup bibir tunanganmu?

(Perburuan, p.90)

Penerjemah menerjemahkannya menjadi:

- Tu es encore soldat, Hardo, et tu le seras toujours. Tu peux jeter aux chiens ta promesse de soldat aux Japonais, mais pas celle que tu as faite devant nous dans la grotte de Sampur. Jamais de la vie! Tu devras lever l'épée quand il le faut! Tirer quand il faudra tirer! Et quand et quand tu auras rempli ton devoir de soldat, et alors seulement, personne ne pourra t'interdire de poser tes lèvres sur les lèvres de ta bienaimée!.

(Le Fugitif, p.117-118)

Sebelumnya, penerjemah menerjemahkannya dengan metode domesticating. Dia menambahkan kata "aux chiens" yang berarti "anjing" untuk menunjukkan kata tersebut kepada prajurit Jepang. Namun dalam versi asli, penulis tidak menyebutkan kata anjing dalam kalimatnya. Penerjemah memberikan penambahan tersebut untuk menggambarkan betapa kejamnya tentara Jepang dan mengibaratkannya seperti binatang, anjing. Berikut digambarkan kemarahan Dipo untuk mengingatkan Hardo.

i. Karmin tak menengok, berteriak lagi ia. Ini aku, shodanco Karmin. Mari bunuh, kawan! Dan mereka tak juga bertindak apa-apa. Mengapa tak mau membunuh? Sekarang ia mengembangkan kedua lengan 
tangannya ke samping kiri dan kanan. Tidak mau? Tanyanya lagi. Tak terjawab. Tidak mau? Ulangnya.

Tiba-tiba terdengar teriak Hardi pada orang-orang itu. Pulang... pulang, semua kalian!

(Perburuan, p.162)

Dalam terjemahannya menjadi :

Karmin ne se retourna pas et cria de nouveau:

- C'est moi le shodanco Karmin. Tuezmoi, les gars!

Mais personne n'avait envie de rien faire.

- Pourquoi ne voulez-vous pas? Il ouvrit tous grands les bras.

- Vous ne voulez pas? Vous ne vouler. pas? Répéta-t-il.

Personne ne répondit

La voix d'Hardo retentit tout à coup:

- Rentrez chez vous, tous tant que vous êtes! Rentrez, chę, vous!

(Le Fugitif, p.208)

Dalam terjemahan ini, penerjemah memberikan gestur yang dalam versi asli "Sekarang ia mengembangkan kedua lengan tangannya ke samping kiri dan kanan". Kalimat ini jika diartikan seharusnya menjadi "maintenant il ouvrit ses deux bras à gauche et à droite". Namun penerjemah hanya menerjemahkannya dengan kalimat "il ouvrit tout grands les bras" yang berarti "dia membuka tangannya lebar-lebar". Sehingga pembaca dapat berimajinasi akan gestur tersebut.

\section{SIMPULAN}

Dalam menerjemahkan dengan menggunakan teori terjemahan postkolonial, penerjemah harus berupaya untuk menyampaikan isi buku sesuai dengan yang aslinya namun dihadapkan oleh unsur-unsur yang bisa diterima oleh pembaca asing. Begitupula jika dihadapkan oleh budaya yang berbeda dengan pembaca asing, maka teknik yang ada pada teori terjemahan budaya untuk dunia ketiga bisa diterapkan.

Untuk membenarkan hipotesis, peneliti telah mengembangkannya di bagian Hasil dan Pembahasan. Dalam analisis bentuk buku serta cover buku, terdapat perubahan,walaupun penerjemah mengubah sampul, namun tetap konsisten pada isi buku. Untuk keseluruhan dari novel Perburuan dan terjemahannya Le Fugitif, peneliti menganalisis bentuk buku-buku ini dan judul buku ini. Perhatian peneliti telah difokuskan pada sampul buku-buku ini. Ilustrasi sampul buku tersebut mengikat nilai sejarah bukubuku ini. Selain itu, ilustrasi sampul juga memberikan pendapat pada sampul buku Perburuan, bahwa ilustrator menggambarkan pengejaran Hardo. Gambar tongkat bambu yang tajam dihubungkan dengan sejarah Indonesia yaitu penggunaan beberapa batang bambu tajam yang digunakan oleh berbagai daerah di Indonesia untuk melambangkan keberanian dan pengorbanan dalam mencapai kemerdekaan. Sebaliknya, ilustrasi dalam buku diterjemahkan, Le Fugitif, memiliki citra Wayang. Tema dalam cerita wayang ini adalah perjuangan. Perjuangan ini tidak hanya antara keinginan baik dan jahat, tapi juga keinginan manusia. Ada benci, cinta, pengorbanan, pengkhianatan, kekejaman dan keramahan. Akibatnya, karakter yang baik adalah karakter yang dapat mengendalikan emosi dan keinginannya.

Peneliti menganalisis pula makna judul buku-buku tersebut yang ternyata tidak sama. Dalam versi asli, judul Perburuan diterjemahkan ke dalam bahasa Perancis sebagai La Chasse (berburu) yang berarti tindakan untuk berburu, mengejar untuk menangkap atau membunuh untuk tujuan utilitarian atau rasa berburu hewan besar. Peneliti berpikir bahwa penulis memberi judul bukunya karena dia ingin menekankan bagaimana Hardo diburu oleh penjajah Jepang dan bagaimana Hardo bersembunyi dari penjajah Jepang. Adapun dalam buku terjemahannya, penerjemah mengubah judul, Le Fugitif. Peneliti menganggap bahwa penerjemah telah difokuskan pada karakter dalam buku yang menjadi buronan. 
Merujuk pada hasil analisis data, secara keseluruhan, dari novel ini, penerjemah mencoba untuk setia dengan versi asli, kadang-kadang membuat katakata dari bahasa sasaran untuk memiliki arti yang sama dari versi asli. Sebagai contoh, penerjemah menyampaikan gagasan suatu kalimat namun ia membuat perubahan dalam struktur kalimat dengan mempertimbangkan teori terjemahan post-kolonial dan teori terjemahan dari budaya Dunia Ketiga. Sehingga berdasarkan hasil pembahasan terjemahan novel Perburuan ini, dapat diketahui bahwa penerjemah merupakan penerjemah setia berdasarkan konteks dan isi dari novel Perburuan.

\section{DAFTAR RUJUKAN}

Asad, T (ed). (1975). Anthropology and the colonial encounter. N.J : Humanities Press, Atlantic Highlands

Basnett, S., \& Trivedi, H. (2002). Post colonial translation: theory and practice. London and New York : Routledge

Bel-et-bien. (t.t.). L'internaute online. dari http://www.linternaute.com/ dictionnaire/fr/definition/bel-etbien/.

Buru. (t. t.). Kamus Besar Babasa Indonesia online. dari http://kbbi.web.id/buru.

Catford J. C (1965). A linguistic theory of translation. London : Oxford University Press.

Chasse. (t.t.). Central national resources textuelles et lexicales online. Dari http://www. cnrtl.fr/definition/chasse

Childs, P., \& Williams, P. (eds). (1997). Introduction to post-colonial theory. New York : Prentice-Hall.

Daillie, F. R. (1991). In Zylberstain, JeanClaude (dir), Le Fugitif. Nivelle : Plon

Delisle, J. (2003). L'bistoire de la traduction: son importance en traductologie, son enseignement au moyen d'un didacticiel multimedia et multilangue, 1(2). Paris: Presses de la Sorbonne nouvelle KSCI
Dingwaney, A \& Maier, C. (eds). (1995). Between languages and cultures : translation and cross-culturals texts. Pittsburgh and London : University of Pittsburgh Press

Fanon, F. (1967). Black skin, white masks. (terj). Charles Lam Markmann. New York : Grove Press, Inc.

Fazil. (2016). Kajian Teori Postkolonial. Diakses tanggal 26 Maret 2016 dari: https:// www.academia.edu/9463603/ Kajian_TEORI_postkolonial.

Fugitif. (t.t.). Central national resources textuelles et lexicales online. dari http://www. cnrtl.fr/definition/fugitif

Isnaeni, H, F. (2014). Setengah mitos bambu runcing (blog). Dari http://historia. $\mathrm{id} /$ modern/setengah-mitos-bamburuncing

Kidwai, S, (2016). Going native at crossroads of translation. The Hindu.

Kurniawan, E. (2002). Pramoedya Ananta Toer dan sastra realisme Sosialis. Yogyakarta : Jendela. .

Lefevere, A. (1992). Translation rewriting and the manipulation of literary fame, London : Routledge. (1992). Translating literature : practice and theory in comperative literature context. New York :MLAA.

Loomba, A. (2005). Colonialism/postcolonialism, London :Routledge.

Rubel, P, G., \& Rosman, A (eds). (2003). Translating cultures : perspectives on translation and anthropology. New York :Oxford International Publishers Ltd.

Rumambi, H. (2011). Inkarnasi tokoh pewayangan dalam novel perburuan. Dari http://baltyra.com/2011/05/27/ inkarnasi-tokoh-pewayangan-dalamnovel-perburuan/.

Toer, P, A. (2002).Perburuan. Jakarta : Hasta Mitra

Venuti, L. (2004). The Translator's invisibility: a bistory of translation. London : Routledge. 
UCAPAN TERIMA KASIH

Jawaharlal Nehru University, atas dukungan, Peneliti mengucapkan terima kasih yang kesabaran dan kebaikannya dengan realisasi mendalam kepada Profesor N. Kamala, penelitian ini. 